\title{
DIÁLOGOS DEL SUR, ENTRE LA ARQUITECTURA Y EL ARTE: REFLEXIONES DE LA HISTORIA DE UNA AMISTAD EN LA TRAYECTORIA DE JORGE OTEIZA Y JAVIER SAENZ DE OIZA
}

\author{
Alona Martínez Pérez* \\ Doctora Arquitecta. Profesora De Montfort-Leicester University \\ https://dx.doi.org/10.12795/astragalo.2018.i25.08
}

Una historia comienza con una pregunta. Quizás a veces esas preguntas no tengan respuesta, o nos lleven a una reflexión, o incluso a un dialogo. En referencia a la obra del Laocoonte nos referimos a una lucha, de un padre con sus hijos, de una serpiente agarrando a los tres, una lucha por la supervivencia. Una obra imponente del arte griego, donde se entiende esa última fase de la escultura griega donde se alza el movimiento expresivo. Una escultura que yo como autora conozco con un detalle preciso, ya que la he dibujado. Lo interesante cuando dibujas el detalle de los pies, y de los cuerpos, es la tensión. La tensión de los hijos para liberarse de la serpiente. Cada movimiento que se observa en los pies cogidos por la serpiente, muestra esa lucha por los hijos por la supervivencia. Los dos hijos al lado de su padre, el Laocoonte es una lucha de titanes. La obra escultórica que se encuentra en los Museos de Vaticano, que fue fuente de inspiración de artistas y arquitectos italianos durante el Renacimiento, demuestra esa relación entre arte y arquitectura. La tensión entre ese padre y ese hijo, similar en muchos casos a ese diálogo entre América y España. La madre y los hijos, la tensión de un mundo nuevo y uno viejo y decadente. Una relación basada en un entendimiento mutuo, pero también en una tensión y en una historia difícil. Así es percibido desde las letras de Eduardo Galeano, contando la historia del nuevo continente desde otra perspectiva, en su obra magistral "Las venas abiertas de América Latina”. Una relación compleja, de mentiras históricas, de lucha por una libertad tras un pasado colonial y la caída de un imperio a finales del siglo XIX en España.

Una relación basada en una historia de dialogo, de viajes comunes, de historias de emi-

* Leicester School of Architecture, De Montfort University, Reino Unido. 
grantes, de tránsito entre estos dos mundos, que comparten un mismo idioma. Pero lleno de matices, y de tiempos diferentes. La metáfora del Laocoonte, bien se puede trasladar a esta relación entre los dos continentes Europa, y América, y entre España y América Latina.

Una historia que comienza por casualidad cuando Cristóbal Colon y los Reyes Católicos deciden buscar una ruta alternativa para Las Indias. Cuando esperaban encontrarse con agua, de repente, llegaron a un nuevo continente. Para mí quizás desde un punto de vista personal entiendo más el espacio común que nos une, como un punto de encuentro. La relación de la emigración entre ambos continentes de personas, de continuas crisis que hacen que ese movimiento ocurra. Crisis continúa entre España y los países de América del Sur, que van y vienen constantemente en un flujo migratorio en búsqueda de mejores oportunidades, en búsqueda de una vida mejor. En el norte de España perviven las casas de los Indianos, incluso en mi propia familia tengo antepasados que huyendo de la pobreza dejaron ese Norte para buscar una nueva vida en Uruguay, en Montevideo. Un viaje breve, creían, pero nunca regresaron a Europa. Una Europa sumida en una crisis económica, y de valores a principios y mediados del siglo XX. Donde el Nuevo Mundo era un mundo, lleno de oportunidades, de innovación. El reflejo de esa relación entre los dos continentes esta aun clara en la arquitectura del Norte de España, con las casas de los Indianos, de las personas que fueron y regresaron y construyeron una arquitectura que reflejaba esa relación entre nuestros dos continentes. Una relación difícil donde el pasado colonial, creó cicatrices que resultaron en la independencia de los países latinoamericanos del con- trol español. Y que en el siglo XX hizo que una emigración entre ambos continentes fuera un flujo continuo de personas, y de historias, de relaciones entre personas, entre artistas, entre arquitectos. Una relación basada en diferencias y puntos en común pero también en una tensión parecida a la de la estatua del Laocoonte. Una relación compleja, difícil, y también distante en ciertos aspectos. Rafael Moneo en su libro "Inquietud teórica y estrategia proyectual en la obra de ocho arquitectos contemporáneos" refiriéndose a la obra de Aldo Rossi habla de la obra del arquitecto italiano en dos fases, una que se refiere al conocimiento y otra al sentimiento. En su obra inicial "La arquitectura de la ciudad" el arquitecto italiano trata de llegar a un tratado de la ciudad desde la perspectiva del estructuralismo, y otra la del sentimiento cuando Rossi al final de su vida está más interesado en imágenes y en su relación personal con la arquitectura que se refleja en su libro “Una autobiografía científica". Partiendo desde ese punto de vista en este artículo querría reflexionar sobre la obra de dos personas cuya obra y vida están relacionadas de la misma forma que la relación entre los dos continentes: el arquitecto navarro Francisco Javier Sáenz de Oiza, y el escultor vasco Jorge Oteiza.

Un relación basada en una amistad, y en una trayectoria común de los dos autores que en este artículo me gustaría hacer hincapié, no solo por la pregunta con la que comenzaba refiriéndome al Laocoonte y esa relación entre la arquitectura y la escultura, pero también por la relación entre esas dos disciplinas en la obra de estos dos autores, pesos pesados de la arquitectura y escultura vasca y española del siglo XX y su relación de ambos en tres obras: el santuario de Aránzazu en Guipúzcoa 
(obra realizada con el arquitecto Luis Laorga), el proyecto no construido de la Alhóndiga en Bilbao, y la Fundación Jorge Oteiza en Navarra.

Desde un punto de vista personal como arquitecta vasca residiendo en el extranjero, estas obras obran para mí -vistas desde una distancia- el reconocimiento universal de la obra de dos autores gigantes del panorama de la arquitectura y escultura vasca. Hice una visita a Aránzazu cuando estudiaba arquitectura en Inglaterra. Eran unas fiestas de Navidades y tres amigos y yo cogimos un coche para llegar al santuario de Aránzazu. El paisaje donde está el monasterio queda en un alto en las montañas de Guipúzcoa, un lugar de acceso difícil. Esta obra imponente representa sin duda un momento importante de la obra de ambos autores. En la memoria del proyecto los arquitectos Sainz de Oiza y Laorga escriben: "Hemos de manejar la pintura mural, el hierro forjado, la madera, la cal, con los que indudablemente puede conseguirse el ambiente propio de un templo de montaña como el que se proyecta" ${ }^{\prime}$. El santuario se integra perfectamente en el territorio donde se asienta, un espacio en la montaña expuesto al clima hostil del territorio. Recuerdo, en la visita, la integración de las esculturas de Oteiza en la fachada del templo. No fue un proyecto que estuvo exento de polémica, finalmente realizado en 1969. Oteiza realizó catorce apóstoles en vez de doce, y la Piedad con su hijo a los pies. El escultor había marchado a Madrid a estudiar arquitectura, dejándolo para matricularse en Medicina, carrera que luego abandonó, para consagrarse a la profesión a la que dedicaría su vida: la escultura. Aránzazu

1 https://www.arantzazu.org/index.php/es/basilica/ arquitectura/basilica-descripcion-y-significado (acceso 09/02/2019) fue para Oteiza un proyecto difícil, y no exento de polémica. Al finalizar el proyecto, tras un trabajo incansable, el artista concluyó: "aquella oportunidad que se me presentaba de poder transmitir mi personal mensaje religioso y vital al enorme muro exterior y frontal de la gran Basílica de Euskal Herria; el mayor honor y la mayor felicidad de mi pobre vida"2. Un proyecto para él tan importante que no abandonó tras la polémica del mismo, pero en el que trabajó incansablemente para finalizarlo. Aquella tarde de sábado tras concluir nuestra visita fuimos a la casa de Oteiza en Zarautz, recuerdo llamar al portero automático, ya que sabíamos que acogía en su casa a estudiantes para hablar de su obra. La señora que le cuidaba nos dijo que el artista había pasado el día en San Juan de Luz y que estaba descansando, pero que podíamos volver otro día. Tristemente, no pudo ser y el artista falleció, pero para mí el recuerdo de esa obra tan imponente, polémica, grandiosa en la fachada del templo, demuestra quizás un momento único en ese arte y arquitectura vasca que se ha convertido en la referencia no solo en el País Vasco sino internacionalmente como la colaboración de dos amigos en las que su amistad estaría invariablemente unida a sus trayectorias, tanto vitales como de producción artística e arquitectónica. Dentro de la historia del proyecto, el ábside lo realizó Lucio Muñoz, y las puertas fueron diseñadas por Eduardo Chillida, artistas que tras esa obra tuvieron carreras muy notables.

La relación de Oteiza con Latinoamérica comienza con su estancia en el continente americano donde combina la escultura con la

2 https://www.arantzazu.org/index.php/es/basilica/ apostolado/fachada-historia-de-su-decoracion (acceso 09/02/2019) 
enseñanza. En esa etapa gana el primer premio importante de su carrera en São Paulo. Escribe el subdirector del Museo Oteiza Juan Pablo Huércanos: "El premio al mejor escultor internacional recibido, en 1957, en la IV Bienal de São Paulo, fue el primer reconocimiento público que recibió su planteamiento escultórico. Le precedieron en esa distinción grandes escultores como Max Bill y Henry Moore, que habian recibido el galardón en ediciones anteriores, constituido en el evento artístico de mayor trascendencia en aquellos años en América"3. Tal premio reconociendo su obra al otro lado del Atlántico demuestra la importancia en el nuevo continente de su trayectoria. Oteiza permaneció en Latinoamérica nueve años, en Perú y en Argentina. Allá se casó con su esposa Itziar Carreño.

Una obra importante y nunca construida fue el proyecto de la Alhóndiga en Bilbao. El proyecto llevaba a cabo la rehabilitación del edifico de Ricardo Bastida, uniéndolo con un solar: "En 1988, el alcalde de Bilbao José María Gorordo invitó al escultor Oteiza a participar en un proyecto de reutilización de la antigua Alhóndiga y el solar del Colegio Santiago Apóstol, uniéndose más tarde los arquitectos Juan Daniel Fullaondo y Francisco Javier Sáenz de Oiza para construir una gran "factoría de arte", que dinamizase cultural y económicamente la ciudad tras su proceso de desindustrialización. El proyecto, que tuvo un alto grado de conceptualización y desarrollo por parte de sus promotores, no fue finalmente edificado y las funciones que debía desem-

3 http://www.unav.es/nuestrotiempo/es/temas/oteizaescultor-que-fabricaba-hombre (acceso 09/02/2019) peñar quedaron insatisfechas"4. Para mí, ese proyecto no construido representa una oportunidad perdida para la ciudad, el "cubo" de Oteiza como se llamaba en la ciudad en la que crecí. Ese proyecto hubiera supuesto la oportunidad al artista y a los arquitectos de dotar a la ciudad de un centro artístico internacional. Más tarde, el proyecto de rehabilitación lo hizo el diseñador francés Philip Starck, con el alcalde Iñaki Azkuna, un proyecto muy distinto al de Oteiza, Chillida y Fullaondo. Una oportunidad perdida como indicaba el mismo Oteiza en una visita a Bilbao: "Este pueblo está arruinado culturalmente. El País Vasco tiene energía más que suficiente para salir adelante en la política, la economía, la industria. Pero la cultura vasca ha sido encorsetada, compartimentada y ahogada por nuestros políticos. Podrán hacerse proyectos magníficos, pero no son más que pequeños parches. Un relanzamiento global de nuestra cultura es ya imposible. Y no se puede hacer nada. [...] El PNV ha trasladado su mediocridad a la política cultural y ya es demasiado tarde para hacer nada, aunque proyectos como el de la Alhóndiga pueden actuar como cataplasmas para atenuar sus efectos"

La última colaboración entre el arquitecto Sainz de Oiza y el escultor Oteiza fue en su casa fundación. Un edificio proyectado en Alzuza en Navarra donde Oteiza vivió los últimos años de su vida, y en Navarra dejo su legado y su obra. Esta obra sería la última obra del arquitecto: "El proyecto arquitectónico desarro-

4 https://www.museooteiza.org/2017/11/nueva-publicacion-oteiza-y-el-centro-cultural-alhondiga-de-bilbao-unainterpretacion-estetica/ (acceso 09/02/2019)

5 http://www.euskonews.eus/0456zbk/gaia45603es.html (acceso 09/02/2019) 
llado por Francisco Javier Sáenz de Oiza responde a la idea genérica de articular una secuencia interrelacionada de espacios de muy distinta escala, presidida por una central y dominante, que por sus proporciones recuerde al túnel que el artista traspasaba en Arantzazu cuando esculpió la estatuaria que jalona el Santuario. Este espacio central cargado de misterio articula la ordenación del resto de las salas, concebidas para acoger el conjunto experimental de Jorge Oteiza y funcionar de acorde con la significación espiritual y metafísica de sus indagaciones acerca del vacío y la desocupación de las formas geométricas" ${ }^{\text {. }}$.

Oteiza puso una condición en ese proyecto y esa fue que la realizara su amigo. El arquitecto ya enfermo diseño la que sería su última obra. En ese proceso explicando la obra decía Sáenz de Oiza: "He partido de la idea del túnel de Arantzazu, donde trabajaba Oteiza, en la oscuridad. Entonces yo he querido hacer un recuerdo a esa nave, haciendo una nave oscura y solemne que se abra al paisaje por abajo" ${ }^{7}$. En esa última obra, Oiza vuelve a esa primera obra a la que me refería en este artículo, el diseño de la fundación retorna al origen de una amistad que comenzó años atrás que unió a dos de los más importantes creadores en la España del siglo XX. En esa tensión con la que comenzaba la lucha en la estatua del Laocoonte de una lucha de dos hijos y su padre con una serpiente, en ese territorio entre el arte y la arquitectura presente en la obra de Jorge Oteiza y Javier Saenz de Oiza, se esconde quizás ese lugar donde la luz encuentra a la arquitectura y al arte, en el pasillo de Arantzazu donde Oteiza trabajaba en la oscuridad.

Agradecimientos: Dr Carlos Tapia (por la invitación, y sus comentarios), Rosa Maria Perez Ruiz (por inculcarme el conocimiento de la obra de Oteiza y Saenz de Oiza).
6 https://www.museooteiza.org/el-edificio/ (acceso 09/02/2019)
7 Imprescindibles- No te mueras sin ir a Ronchamp (Sainz de Oiza). (2018). Radio Televisión Española, 09 Diciembre 2018 , http://www.rtve.es/alacarta/videos/imprescindibles/imprescindibles-no-mueras-sin-ir-ronchamp-saenzoiza/4881972/ 


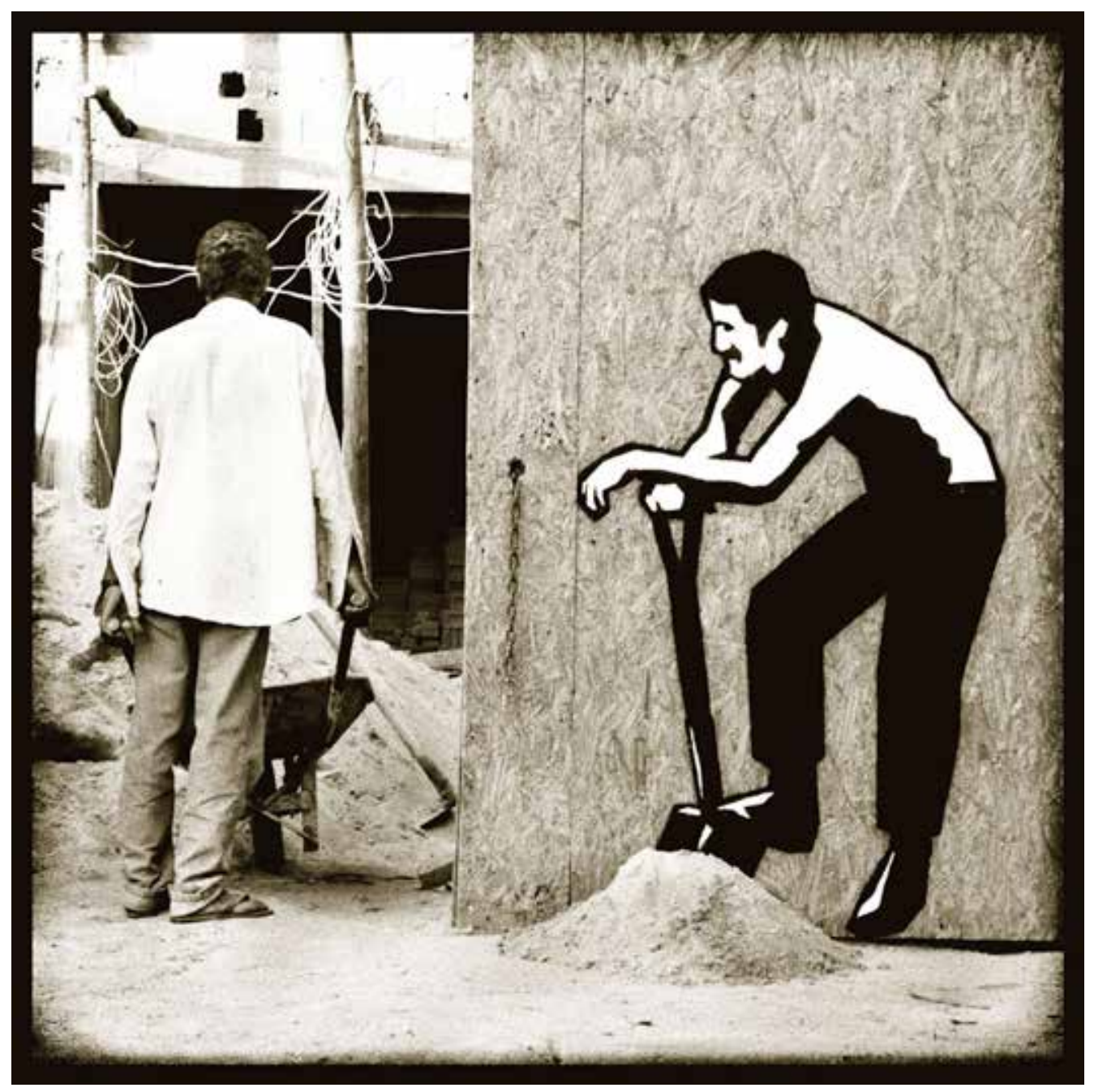

Metabiótica 18. 2005. Intervenção urbana seguida de registro fotográfico 